\title{
METODOLOGIA DE ELABORAÇÃO DO PLANO DE PREVENÇÃO CONTRA INCÊNDIO PARA EDIFICAÇÕES E CENTROS COMERCIAIS ${ }^{1}$
}

\author{
METHODOLOGY FOR PREPARING THE FIRE PREVENTION PLAN \\ FOR BUILDINGS AND COMMERCIAL CENTERS
}

\section{Leonardo Fernandes Londero ${ }^{2}$ e William Leonardo da Silva ${ }^{3}$}

\section{RESUMO}

O Plano de Prevenção Contra Incêndio (PPCI) consiste em um plano obrigatório, exigido por órgão público e necessário para todas as edificações e centros comerciais existentes, a fim de proteger a vida dos ocupantes e as edificações através de ações que evitem a propagação do fogo e reduzam os danos materiais causados em uma situação de incêndio. Assim, o presente trabalho estabelece uma metodologia para elaboração de um PPCI, aplicado para edificações e centros comerciais, indicando as principais etapas que devem contemplar nesse programa, como saída de emergência, iluminação de emergência, sinalização de emergência, sistema de detecção e alarme de incêndio, brigada de incêndio e Sistema de Proteção Contra Descargas Atmosféricas (SPDA), sistema de extintores, sistema de hidrantes e mangotinhos e sistema de chuveiros automáticos. Por conseguinte, destaca-se a extrema importância da elaboração do PPCI para edificações e centros comerciais, a fim de evitar incêndios e preservar humanisticamente a vida humana e economicamente as partes envolvidas.

Palavras-chave: proteção, normativas, vistoria.

\section{ABSTRACT}

The Fire Prevention Plan (FPP) consists on a mandatory plan, required by a public agency and necessary for all existing buildings and shopping centers, in order to protect the lives of the occupants and buildings through actions that prevent the spread of fire and reduce material damage caused in a fire situation. Thus, the present work brings a methodology for the elaboration of a FPP. This methodology is applied to buildings and commercial centers, indicating the main steps that should be included in this program. This steps are emergency exit, emergency lighting, emergency signaling, detection and alarm system fire, fire brigade and Lightning Protection System (LPS), fire extinguisher system, hydrants and hosepipe system and automatic shower system. Consequently, it is extremely important to develop the FPP for buildings and shopping centers, in order to avoid tragedies with fires and to preserve humanistically human life and economically the parties involved.

Keywords: protection, normative, surveys.

\footnotetext{
${ }^{1}$ Trabalho Final da especialização em Engenharia de Segurança do Trabalho da Universidade Franciscana - UFN

${ }^{2}$ Engenheiro Químico. Aluno do curso de especialização em Engenharia de Segurança do Trabalho da Universidade Franciscana - UFN. E-mail: leolondero@yahoo.com.br

${ }^{3}$ Orientador. Engenheiro Químico. Docente do curso de Engenharia Química-Universidade Franciscana - UFN. E-mail: w.silva@ufn.edu.br
} 


\section{INTRODUÇÃO}

Historicamente, pode-se identificar uma série de acidentes envolvendo incêndios em edificações e centros comerciais, trazendo consequências como perdas humanas e prejuízos financeiros. Por exemplo, os incêndios edifício Andraus (causando 16 mortes e 320 feridos em 1972), edifício Joelma (causou 187 mortes e mais de 300 feridos em 1974), ambos na cidade de São Paulo (Brasil) e, o mais recente (2013), na cidade de Santa Maria, na Boate Kiss, com 242 vítimas e centenas de feridos. Assim, destaca-se a importância dos cuidados como formar de prevenção, a fim de evitar ou minimizar os acidentes com incêndio através da eliminação dos fatores de riscos (BONITESE, 2007).

Além disso, normas e códigos foram surgidos relacionados com a segurança contra o incêndio, a partir desse cenário de acidentes, como as leis complementares do Estado do Rio Grande do Sul14.376/2013 (estabelece normas sobre Segurança, Prevenção e Proteção contra Incêndios nas edificações e áreas de risco de incêndio), 14.555/2014 (altera a lei complementar 14.376/2013) e 13.425/2017 (Lei “Boate Kiss" que estabelece medidas de prevenção e combate a incêndio e a desastres em estabelecimentos, edificações e áreas de reunião de público) (RIO GRANDE SO SUL, 2013; RIO GRANDE DO SUL, 2013; BRASIL, 2017).

Assim, o Plano de Prevenção e Proteção Contra Incêndio (PPCI) consiste em um processo que contém os elementos formais, que todo proprietário ou responsável pelas áreas de risco de incêndio e edificações deve encaminhar ao Corpo de Bombeiros Militar do Rio Grande do Sul, conforme orientações do referido órgão, memoriais, laudos com suas respectivas ARTs (Anotação de Responsabilidade Técnica) e plantas com os detalhamentos dos sistemas citados, usando simbologia padrão. Além disso, o mesmo deve ser realizado por Engenheiro ou Arquiteto devidamente habilitado, de preferência com uma equipe multidisciplinar, para uma maior abrangência de conhecimento de áreas diversas, com o intuito de agregar mais conhecimento e soluções ao projeto.

Segundo Telmo Brentano (2015), o PPCI proporciona ganhos em relação a vida humana, prevenindo e evitando o incêndio, bem como destaca a sua importância financeira, através da maior rapidez na execução, maior economia de materiais e mão de obra, maior rigidez das instalações, menos gastos com manutenção e satisfação do cliente. Além disso, tem como principais objetivos a proteção da vida humana, do patrimônio e, por final a continuidade do processo produtivo. Assim, a elaboração do PPCI de uma edificação deve ser focada em duas premissas básicas (PALMA, 2016): (i) evitar o início do fogo e havendo a ocorrência de foco de fogo, devem ser previstos meios apropriados para confinar o fogo no seu local de origem e (ii) permitir a desocupação da edificação com segurança e rapidez, facilitando o acesso e o combate ao fogo de forma rápida e eficaz.

As medidas de proteção contra incêndio para edificações e centros comerciais podem ser classificadas, como ativas (ou de combate), que são aquelas tomadas quando o fogo já está ocorrendo, e/ou passivas, que são aquelas tomadas durante a fase de elaboração do projeto arquitetônico e de seus 
complementares, a fim de evitar/reduzir ao máximo a ocorrência de um foco de fogo, bem como as condições propícias para o seu crescimento e alastramento (BRENTANO, 2010):

Neste contexto, o presente trabalho tem por objetivo apresentar uma metodologia para elaboração de um Programa de Prevenção Contra Incêndio (PPCI), aplicado para edificações e centro comerciais, em qualquer local, indicando as principais etapas que devem contemplar nesse programa.

\section{ELABORAÇÃO DO PPCI}

Para a elaboração do projeto de prevenção contra incêndio, é necessário seguir algumas resoluções técnicas, de acordo com as determinações de cada estado brasileiro e do Corpo de Bombeiros Militar, determinadas pela Associação Brasileira de Normas Técnicas (ABNT). Para o Estado do Rio Grande do Sul, utiliza-se a Resolução Técnica de Transição (CBMRS, 2017), elencando os itens mínimos exigidos nas edificações e centros comerciais, com as respectivas resoluções técnicas, conforme a Tabela 1 .

Tabela 1 - Principais resoluções técnicas e itens de segurança contra incêndio em edificações e centros comerciais.

\begin{tabular}{|c|c|}
\hline Item & Resolução técnica \\
\hline Acesso de viaturas de bombeiros & $\begin{array}{l}\text { Instrução Técnica n. }{ }^{\circ} \text { 06, do Corpo de Bombeiros } \\
\text { da Polícia Militar do Estado de São Paulo }\end{array}$ \\
\hline Compartimentação horizontal e vertical & $\begin{array}{l}\text { Instrução Técnica n. }{ }^{\circ} \text { 09, do Corpo de Bombeiros } \\
\text { da Polícia Militar do Estado de São Paulo }\end{array}$ \\
\hline Controle de fumaça & $\begin{array}{l}\text { Instrução Técnica n. }{ }^{\circ} \text { 15, do Corpo de Bombeiros } \\
\text { da Polícia Militar do Estado de São Paulo }\end{array}$ \\
\hline Controle de materiais de acabamento e revestimento & $\begin{array}{l}\text { Instrução Técnica n. }{ }^{\circ} 10 \text {, do Corpo de Bombeiros } \\
\text { da Polícia Militar do Estado de São Paulo }\end{array}$ \\
\hline Detecção e alarme de incêndio & ABNT NBR 17240 e NBR ISO 7240 \\
\hline Hidrantes e mangotinhos & ABNT NBR 13714 \\
\hline Iluminação de emergência & ABNT NBR 10898 \\
\hline $\begin{array}{l}\text { Instalações Automáticas de Extinção de Incêndio - } \\
\text { Chuveiros Automáticos }\end{array}$ & ABNT NBR 10897 \\
\hline Plano de emergência & ABNT NBR 15219 \\
\hline Segurança Estrutural em Incêndio & $\begin{array}{l}\text { Instrução Técnica n. }{ }^{\circ} \text { 08, do Corpo de Bombeiros } \\
\text { da Polícia Militar do Estado de São Paulo }\end{array}$ \\
\hline Sinalização de emergência & $\begin{array}{l}\text { ABNT 13434-1, ABNT NBR 13434-2 e } \\
\text { ABNT NBR 13434-3 }\end{array}$ \\
\hline $\begin{array}{l}\text { Sistema de Proteção Contra Descargas } \\
\text { Atmosféricas - SPDA }\end{array}$ & ABNT NBR 5419 \\
\hline Brigada de incêndio & $\begin{array}{l}\text { Resolução Técnica n. }{ }^{\circ} \text { 014/BM-CCB/2009 e suas } \\
\text { atualizações }\end{array}$ \\
\hline Extintores de incêndio & $\begin{array}{l}\text { Resolução Técnica CBMRS n. }{ }^{\circ} \text { 14/2016 - } \\
\text { Extintores de Incêndioe suas atualizações }\end{array}$ \\
\hline Saídas de emergência & $\begin{array}{l}\text { Resolução Técnica CBMRS n. }{ }^{\circ} 11 \text { - Parte 01/2016 } \\
\text { - Saídas de Emergênciae suas atualizações }\end{array}$ \\
\hline Hidrante urbano & $\begin{array}{l}\text { Resolução Técnica CBMRS n. }{ }^{\circ} \text { 16/2017 - } \\
\text { Hidrante Urbano e suas atualizações }\end{array}$ \\
\hline
\end{tabular}

Fonte: Adaptado do CBMRS, 2017. 
A seguir serão descritos alguns desses itens necessários para o PPCI em edificações localizadas em centros urbanos.

\section{SAÍDAS DE EMERGÊNCIA}

As saídas de emergência são caminhos contínuos e seguros que devem ser percorridos pelas pessoas em casos de incêndio até chegar a um espaço livre exterior (ABNT 9077, 2001). Assim, é constituído por portas, corredores, halls, passagens externas, balcões, sacadas, vestíbulos, escadas, rampas ou outros dispositivos de saída. (EUZEBIO, 2011). Segundo a NBR 9077 (2001), são definidos os principais itens de segurança:

- Larguras das saídas de emergência: corresponde aos acessos, escadas, descargas, dentre outros, é dada pela Equação (1).

$$
N=\frac{P}{C}
$$

Onde:

$\mathrm{N}$ = número de unidades de passagem, arredondado para número inteiro;

$\mathrm{P}=$ população;

$\mathrm{C}=$ capacidade da unidade de passagem.

Além disso, as larguras mínimas das saídas, em qualquer caso, devem ser as seguintes:

(a) 1,10 m, correspondendo a duas unidades de passagem e $55 \mathrm{~cm}$, para as ocupações em geral;

(b) 2,20 m, para permitir a passagem de macas, camas, e outros, nas ocupações do grupo H (serviço de saúde e institucional), divisão H-3 (hospital e assemelhado, como casa de saúde, prontos-socorros, clínicas com internação, ambulatórios e postos de atendimento de urgência, postos de saúde e puericultura e assemelhados com internação).

\section{- Distâncias máximas a serem percorridas em caso de incêndios (rotas de fuga):}

As distâncias máximas a serem percorridas para atingir um local seguro (espaço livre exterior, área de refúgio, escada protegida ou à prova de fumaça), tendo em vista o risco à vida humana decorrente do fogo e da fumaça, devem considerar:

(a) o acréscimo de risco quando a fuga é possível em apenas um sentido;

(b) o acréscimo de risco em função das características construtivas da edificação;

(c) a redução de risco em caso de proteção por chuveiros automáticos;

(d) a redução de risco pela facilidade de saídas em edificações térreas. 
A Tabela 2 apresenta as distâncias máximas a serem percorridas

Tabela 2 - Distâncias máximas a serem percorridas conforme o tipo de edificação.

\begin{tabular}{cccccc}
\hline \multirow{2}{*}{ Edificação } & \multirow{2}{*}{ Grupo e divisão de ocupação } & \multicolumn{2}{c}{ Sem chuveiros automáticos } & \multicolumn{2}{c}{ Com chuveiros automáticos } \\
\cline { 3 - 6 } & & Saída única & Mais de uma saída & Saída única & Mais de uma saída \\
\hline $\mathrm{X}$ & Qualquer & $10 \mathrm{~m}$ & $20 \mathrm{~m}$ & $25 \mathrm{~m}$ & $35 \mathrm{~m}$ \\
$\mathrm{Y}$ & Qualquer & $20 \mathrm{~m}$ & $30 \mathrm{~m}$ & $35 \mathrm{~m}$ & $45 \mathrm{~m}$ \\
\multirow{2}{*}{$\mathrm{Z}$} & $\mathrm{C}, \mathrm{D}, \mathrm{E}, \mathrm{F}, \mathrm{G}-3, \mathrm{G}-4, \mathrm{G}-5, \mathrm{H}$ e I & $30 \mathrm{~m}$ & $40 \mathrm{~m}$ & $45 \mathrm{~m}$ & $55 \mathrm{~m}$ \\
& $\mathrm{~A}, \mathrm{~B}, \mathrm{G}-1, \mathrm{G}-2 \mathrm{e} \mathrm{J}$ & $40 \mathrm{~m}$ & $50 \mathrm{~m}$ & $55 \mathrm{~m}$ & $65 \mathrm{~m}$ \\
\hline
\end{tabular}

Fonte: Adaptado da NBR 9077, 2001.

X: edificações em que a propagação do fogo é fácil; Y: edificações com mediana resistência ao fogo; $Z$ : edificações em que a propagação do fogo é difícil.

A: residencial; B: serviços de hospedagem; C: comercial varejista; $\mathrm{D}$ : serviços profissionais, pessoais e técnicos; E: educacional e cultura física; F: locais de reunião de público; G-1: garagens sem acesso de público e sem abastecimento; G-2: garagem com acesso ao público e sem abastecimento; G-3: locais dotados de abastecimento de combustível; G-4: serviços de conservação, manutenção e reparos; H: serviços de saúde e institucionais; I: industrial, comercial de alto risco, atacadista e depósitos e J: depósitos de baixo risco.

Além disso, destaca-se que a NBR 9077/2001 estabelece o número de saída de emergências, bem como a exigência de alarme de incêndio. Além disso, as formas de propagação do fogo, como subterrâneo, superficial e/ou aéreo, tendo com principais fatores que influenciam na sua propagação a quantidade, tipo e arranjo do material combustível, umidade do material combustível, condições climáticas e topografia (BRENTANO, 2015).

\section{ILUMINAÇÃO DE EMERGÊNCIA}

Consiste no conjunto de equipamentos e componentes que são destinados para substituir a iluminação artificial normal, quando desligada numa situação de incêndio, a fim de proporcionar iluminação suficiente e adequada, bem como permitir a saída fácil e segura das pessoas (UMINSKI, 2003). A NBR 10898/99 fixa as características mínimas exigíveis para as funções a que se destina o sistema de iluminação de emergência a ser instalado em edificações, ou em outras áreas fechadas sem iluminação natural, estabelecendo: (i) a distância máxima entre dois pontos de iluminação de ambiente deve ser equivalente a quatro vezes a altura da instalação destes em relação ao nível do piso e nunca deve ultrapassar 15 m e; (ii) a distância máxima entre o ponto de iluminação e a parede não deve ultrapassar 7,5 m. Para a elaboração de projeto de iluminação de emergência, instalação, manutenção do sistema e demais orientações, deve-se: 
(a) permitir o controle visual das áreas abandonadas para localizar pessoas impedidas de locomover-se;

(b) manter a segurança patrimonial para facilitar a localização de estranhos nas áreas de segurança pelo pessoal da intervenção;

(c) sinalizar inconfundivelmente as rotas de fuga utilizáveis no momento do abandono do local;

(d) sinalizar o topo do prédio para a aviação comercial.

Além disso, o sistema de iluminação de emergência pode ser classificado basicamente quanto às fontes de energia a serem utilizadas, em:

- Sistema centralizado de acumuladores: composto por central de comando (painel de controle), acumuladores de energia (baterias), rede de alimentação (instalação elétrica), e luminárias;

- Grupo motogerador: composto por um grupo motogerador automatizado, painel de controle, rede de alimentação e luminárias;

- Conjunto de blocos autônomos: são aparelhos com lâmpadas incandescentes ou fluorescentes, contendo pequenas baterias e os dispositivos necessários para colocá-lo em funcionamento. É o sistema mais comumente utilizado em edificações.

\section{SINALIZAÇÃO DE EMERGÊNCIA}

A sinalização de emergência deve ser constituída pelo conjunto de sinais visuais, seja por símbolos, mensagens e cores, convenientemente localizados no interior da edificação, a fim de reduzir o risco da ocorrência de incêndio, alertar sobre os locais com riscos potenciais de fogo e garantir que sejam adotadas ações rápidas adequadas à situação (FAGUNDES, 2013).

Os detalhes de projeto e instalação da sinalização de emergência nas edificações estão nas duas partes da NBR 13434/2004, que padroniza as formas, as dimensões e as cores da sinalização de segurança contra incêndio e pânico utilizada em edificações, assim como apresenta os símbolos adotados. Assim, as dimensões básicas da sinalização devem ser dimensionadas, conforme a Equação (2).

$$
A>\frac{L^{2}}{2000}
$$

Onde:

$\mathrm{A}=$ área da placa $\left(\mathrm{m}^{2}\right)$;

$\mathrm{L}=$ distância do observador à placa $(\mathrm{m})$.

Esta relação é válida para $\mathrm{L}<50 \mathrm{~m}$, sendo que deve ser observada a distância mínima de $4 \mathrm{~m}$, conforme Quadro 1. 
Quadro 1- Dimensões das placas de sinalização.

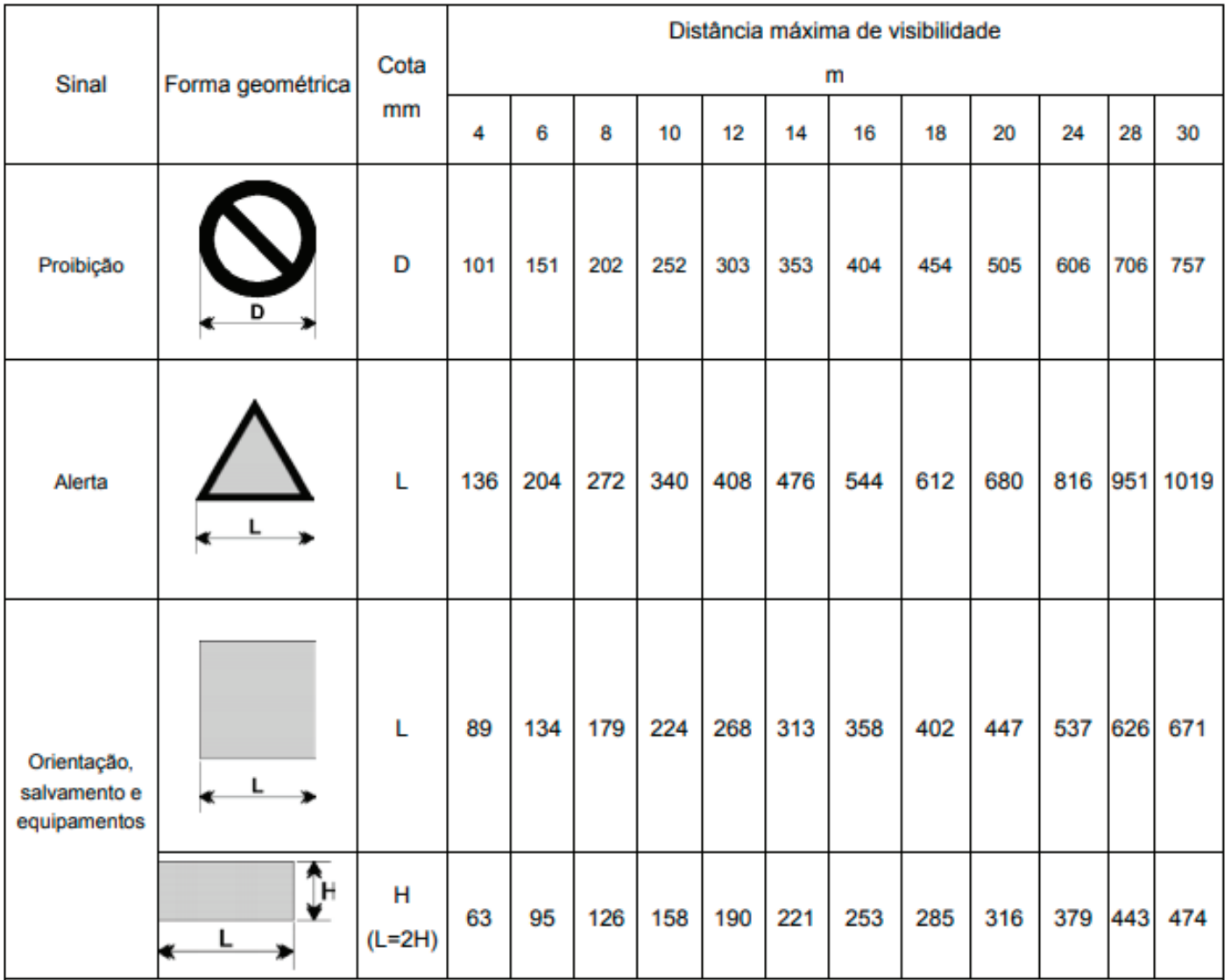

Fonte: Adaptado da NBR 13434, 2004

A Tabela 3 apresenta valores de altura de letra para distâncias predefinidas, destacando que todas as palavras e sentenças devem apresentar letras em caixa alta, fonte Univers 65 ou Helvetica Bold, em local de fácil visualização e leitura (geralmente acima/superior .ao local a ser sinalizado).

Tabela 3 - Altura mínima das letras em placas de sinalização em função da distância de leitura.

\begin{tabular}{|cc|}
\hline Altura mínima $(\mathbf{m m})$ & Distância do leitor com maior impacto $(\mathbf{m})$ \\
\hline 30 & 4 \\
50 & 6 \\
65 & 8 \\
70 & 9 \\
\hline 85 & 10 \\
100 & 12 \\
135 & 16 \\
150 & 18 \\
\hline 200 & 24 \\
210 & 25 \\
225 & 27 \\
250 & 30 \\
300 & 36 \\
350 & 42 \\
\hline
\end{tabular}




\begin{tabular}{|c|c|}
\hline 400 & 48 \\
\hline 500 & 60 \\
\hline 600 & 72 \\
\hline 700 & 84 \\
\hline 750 & 90 \\
\hline 800 & 96 \\
\hline 900 & 108 \\
\hline 1000 & 120 \\
\hline 1500 & 180 \\
\hline
\end{tabular}

Fonte: Adaptado da NBR 13434, 2004.

\section{SISTEMA DE DETECÇÃO E ALARME DE INCÊNDIO}

É um sistema automático de detecção constituído por um conjunto de dispositivos que, quando sensibilizados por fenômenos físicos ou químicos resultantes de uma combustão, como chamas, calor, gases ou fumaça, acionam outros dispositivos (alarmes), que alertam os ocupantes do local sobre a existência de fogo na edificação (SILVEIRA, 2011).

O projeto de sistemas de detecção e alarme de incêndio deve conter todos os elementos necessários ao seu completo funcionamento, de forma a garantir a detecção de um princípio de incêndio, no menor tempo possível (NBR 17240/2010). Com base nos dados levantados na fase de planejamento, devem ser definidos o tipo de sistema de detecção e o tipo de detector apropriado para cada ambiente a ser protegido, levando-se em consideração a sensibilidade do detector e o tempo de resposta do sistema.

Sobre os tipos de sistemas de detecção, têm-se: (a) sistema de detecção convencional; (b) sistema de detecção endereçável; (c) sistema de detecção analógico e (d) sistema de detecção algorítmico. Sobre o projeto executivo deve conter no mínimo as informações seguintes (NBR 17240/2010):

- desenho indicando a localização de todos os equipamentos do sistema e o seu esquema típico de instalação.

- independentemente do tipo de sistema escolhido, a distribuição da central e equipamentos;

- especificação dos equipamentos e as características dos materiais de instalação;

- trajeto dos condutores elétricos nas diferentes áreas, com identificação do material combustível do ambiente a ser protegido, diâmetros dos eletrodutos, caixas e identificação dos bornes de ligação de todos os equipamentos envolvidos;

- diagrama multifilar típico, mostrando uma interligação entre todos os equipamentos dos circuitos de detecção, alarme e comando, e entre estes e a central;

- lista completa de equipamentos, contendo descrição, modelo, fabricante e quantidade;

- cálculo de fontes de alimentação e baterias;

- quadro resumo da instalação,

- manuais de operação, manutenção preventiva e corretiva do sistema, com instruções completas de todas as operações, comandos e ferramentas necessárias. 
A instalação de equipamentos de proteção nas edificações não garante que, no caso de um foco de incêndio, ele seja extinto ainda no princípio. Por isso, é necessário e imprescindível que os ocupantes tenham conhecimentos básicos sobre a operação desses equipamentos e saibam agir ordenadamente, atuando de forma eficaz durante uma situação de emergência. Para esse propósito, existem as brigadas de incêndio, que são um grupo de pessoas, voluntárias ou não (empresas), treinadas em combate a incêndio e prestação de primeiros socorros (BRIGADA, 2015).

A composição da brigada de incêndio de cada edificação ou centro comercial avalia a população fixa, o grau de risco e os grupos/divisões de ocupação da planta, conforme Anexo da NBR 14276/2006. Além disso, os candidatos a brigadista devem ser selecionados atendendo ao maior número de critérios descritos a seguir:

(a) permanecer na edificação durante seu turno de trabalho;

(b) possuir boa condição física e boa saúde;

(c) possuir bom conhecimento das instalações;

(d) ter mais de 18 anos;

(e) ser alfabetizado;

(f) ter treinamento completo (Treinamento de Prevenção e Combate a Incêndio), com aproveitamento mínimo de 70\% na avaliação teórica e prática, com duração máxima de 12 meses.

Conforme Brigada (2015), devem ser realizados exercícios simulados de abandono de área, parciais e completos, na edificação, com a participação de todos os ocupantes, sendo recomendada uma periodicidade máxima de um ano para simulados completos, com a elaboração de ata, contemplando: (a) data e horário do evento; (b) tempo gasto no abandono; (c) tempo gasto no retorno; (d) atuação dos profissionais envolvidos; (e) comportamento da população; (f) tempo gasto para a chegada do Corpo de Bombeiros, quando for possível a sua participação; (g) ajuda externa (como PAM - Plano de Auxílio Mútuo); (h) falha de equipamentos; (i) falhas operacionais e; (j) demais problemas levantados na reunião.

\section{SISTEMA DE EXTINTORES}

O sistema de combate por extintores de incêndio é considerado um sistema móvel, portátil, que necessita de um operador que desloca o equipamento em questão até o local do fogo para extingui-lo (GOMES, 2014). A NBR 12693/2013 estabelece os requisitos exigíveis para projeto, seleção e instalação de extintores de incêndio portáteis e sobre rodas, em edificações e áreas de risco, para combate a princípio de incêndio. 
De acordo com o agente extintor, o princípio de extinção e o sistema de expulsão, os extintores são classificados conforme a Tabela 4.

Tabela 4 - Classificação dos extintores segundo o agente extintor, o princípio de extinção e o sistema de expulsão.

\begin{tabular}{|c|c|c|c|c|c|}
\hline \multirow[b]{2}{*}{ Agente extintor } & \multirow[b]{2}{*}{ Princípio de extinção } & \multicolumn{4}{|c|}{ Sistema de expulsão } \\
\hline & & Autogeração & $\begin{array}{c}\text { Auto- } \\
\text {-expulsão }\end{array}$ & $\begin{array}{l}\text { Pressurização } \\
\text { indireta }\end{array}$ & $\begin{array}{c}\text { Pressurização } \\
\text { direta }\end{array}$ \\
\hline Água & Resfriamento & & & & \\
\hline Soda-ácido & Resfriamento & & & & \\
\hline Espuma química & Abafamento e resfriamento & & & & \\
\hline Carga líquida & Resfriamento & & & & \\
\hline Espuma mecânica & Abafamento e resfriamento & & & & \\
\hline Pó químico $\mathrm{B} / \mathrm{C}$ & Reação química & & & & \\
\hline Pó químico A/B/C & Reação química e abafamento & & & & \\
\hline Pó químico D & $\begin{array}{c}\text { Reação química, abafamento e } \\
\text { resfriamento }\end{array}$ & & & & \\
\hline Gás carbônico $\left(\mathrm{CO}_{2}\right)$ & Abafamento e resfriamento & & & & \\
\hline $\begin{array}{l}\text { Hidrocarbonetos halo- } \\
\text { genados }\end{array}$ & Reação química e abafamento & & & & \\
\hline
\end{tabular}

Fonte: Adaptado da NBR 12693, 2013.

Além disso, os extintores deverão respeitar as exigências das Normas do INMETRO, quanto as suas características físicas e capacidade, devendo ser localizados e instalados de acordo com as exigências do Corpo de Bombeiros Oficial. Além disso, o número mínimo calculado de extintores deve ser colocado estrategicamente em toda a edificação, respeitando a distância mínima a percorrer de 75 pés (23 m), desde qualquer ponto até um extintor (NBR 12693, 2013).

\section{SISTEMA DE HIDRANTES E MANGOTINHO}

O sistema de hidrantes e mangotinho são equipamentos fixos, formados por uma rede de canalização e abrigos ou caixas de incêndio, que contêm tomadas de incêndio com uma ou duas saídas de água, válvulas de bloqueio, mangueiras de incêndio, esguichos e outros equipamentos instalados em locais estratégicos da edificação (NBR 13714, 2000). Além disso, as tubulações do sistema de hidrantes serão destinadas exclusivamente ao serviço de proteção contra incêndio. Destaca-se que os pontos de tomada de água devem ser posicionados:

(a) nas proximidades das portas externas e/ou acessos à área a ser protegida, a não mais de 5 m;

(b) em posições centrais nas áreas protegidas;

(c) fora das escadas ou antecâmaras de fumaça;

(d) de $1,0 \mathrm{~m}$ a $1,5 \mathrm{~m}$ do piso.

Além disso, nos hidrantes externos, quando afastados de no mínimo $15 \mathrm{~m}$ ou $1,5 \mathrm{vez}$ a altura da parede externa da edificação a ser protegida, poderão ser utilizados até $60 \mathrm{~m}$ de mangueira 
(preferencialmente em lances de $15 \mathrm{~m}$ ), desde que devidamente dimensionados hidraulicamente. Recomenda-se que sejam utilizadas mangueiras de $65 \mathrm{~mm}$ de diâmetro para redução da perda de carga do sistema e o último lance de $40 \mathrm{~mm}$ para facilitar seu manuseio. Para cada ponto de hidrante ou de mangotinho, são obrigatórios os materiais conforme a Tabela 5.

Tabela 5 - Tipos de sistemas (hidrante ou mangotinho).

\begin{tabular}{|c|c|c|c|c|c|}
\hline \multirow{2}{*}{ Tipo } & \multirow{2}{*}{ Esguicho } & \multicolumn{2}{|c|}{ Mangueiras } & \multirow{2}{*}{ Saídas } & \multirow{2}{*}{ Vazão (L/min) } \\
\hline & & Diâmetro (mm) & Comprimento máximo (m) & & \\
\hline 1 & Regulável & 25 ou 32 & 30 & 1 & 80 ou 100 \\
\hline 2 & Jato compacto ( $\phi 16 \mathrm{~mm}$ ou regulável) & 40 & 30 & 2 & 300 \\
\hline 3 & Jato compacto ( $\phi 25 \mathrm{~mm}$ ou regulável) & 65 & 30 & 2 & 900 \\
\hline
\end{tabular}

Fonte: Adaptado da NBR 13714, 2000.

\section{SISTEMA DE CHUVEIROS AUTOMÁTICOS}

São sistemas fixos, formados por uma rede de canalização com chuveiros automáticos acoplados, devidamente espaçados e distribuídos por toda a edificação com distanciamentos máximos de acordo com o grau de risco determinado por norma. Podem ser ativados por calor ou fumaça e descarregam água sobre a área de incêndio, alimentados por um sistema de bombas de incêndio ou de reserva de água exclusivos. De acordo com Decreto Estadual no 38.273/98, em seu Art. $8^{\circ}$ do Anexo Único, as edificações deverão ser dotadas de sistemas automáticos de extinção de incêndios conforme a seguinte classificação:

- prédios classificados como de risco grande, que possuam área construída acima de $1.500 \mathrm{~m}^{2}$;

- prédios classificados como área de risco médio que possuam área construída acima de $3.000 \mathrm{~m}^{2}$ ou mais de $20 \mathrm{~m}$ de altura;

- prédios classificados como de risco pequeno que possuam área construída acima de $5.000 \mathrm{~m}^{2}$ ou $30 \mathrm{~m}$ de altura, exceto os residenciais;

- prédios classificados como de risco grande ou médio, quando estiverem abaixo do nível da soleira de entrada e com área superior a $500 \mathrm{~m}^{2}$.

\section{CONCLUSÃO}

Com o presente trabalho foi possível compreender a metodologia de um Projeto de Prevenção de Incêndio para edificações e centros comerciais, de forma geral, destacando principais itens (saídas de emergência, iluminação de emergência, sinalização de emergência, sistema de detecção e alarme de incêndio, brigada de incêndio e SPDA, sistema de extintores, sistema de hidrantes e mangotinhos e sistema de chuveiros automáticos), destacando suas respectivas normativas e legislações. Destaca-se que após a elaboração do PPCI, deve ser solicitada a vistoria do local com risco de incêndio pelo 
Corpo de Bombeiros (CBMRS), para a verificação in loco da execução das medidas de segurança contra incêndio, caso sejam constatadas inconformidades durante a vistoria da edificação, Notificação de Correção de Vistoria (NCV) será emitida, contendo todas as irregularidades, com o prazo de 30 (trinta) dias para sanar as irregularidades e atestar o atendimento à NCV. Por conseguinte, é de extrema importância seguir todos os passos que constam na legislação, para que não se tenha nenhuma chance de novas ocorrências como a da Boate Kiss ou do Edifício Joelma.

\section{REFERÊNCIAS}

ABNT - Associação Brasileira de Normas Técnicas. NBR 9077: Saídas de Emergência em Edifícios. 2001.

. NBR 13434: Sinalização de segurança contra incêndio e pânico. 2004.

. NBR 17240: Sistemas de detecção e alarme de incêndio - Projeto, instalação, comissionamento e manutenção de sistemas de detecção e alarme de incêndio - Requisitos. 2010.

. NBR 14276: Brigada de incêndio. 2006.

. NBR 5419: Proteção de estruturas contra descargas atmosféricas. 2001.

. NBR 12693: Sistemas de proteção por extintores de incêndio. 2013.

BRASIL. Decreto-Lei n ${ }^{\circ}$ 13.425, de 30 de março de 2017. Diário Oficial da República Federativa do Brasil, Poder Executivo, Brasília, DF, 30 mar. 2017. Disponível em: https://bit.ly/30sT6cY. Acesso em: 17 mar. 2020.

BRENTANO, T. A proteção contra incêndio ao projeto de edificações. 2. ed. Porto Alegre: T Edições, 2010.

Instalações hidráulicas de combate a incêndios nas edificações. 5. ed. Porto Alegre:

T Edições, 2015.

BRIGADA. Informativo da brigada de incêndio e emergências da FCFRP. São Paulo, 2015. 
CORPO DE BOMBEIROS MILITAR DO RIO GRANDE DO SUL, Resolução técnica de transição

CBMRS 2017. Disponível em: https://bit.ly/3keQHKZ. Acesso em: 17 mar. 2020.

EUZEBIO, S.C. PPCI fácil: manual completo de prevenção de incêndios. 1. ed. Porto Alegre: Livraria Vicenzo, 2011.

FAGUNDES, F. Plano de prevenção e combate a incêndios: Estudo de caso em edificação residencial multipavimentada. 2013. 71 f. Monografia (Departamento de Ciências Exatas e Engenharias), Universidade Regional do Noroeste do Estado do Rio Grande do Sul, URNRS, Santa Rosa, 2013.

GOMES, T. Projeto de prevenção e combate a incêndio. 2014. 94f. Monografia (Departamento de Engenharia Civil), Universidade Federal de Santa Maria - UFSM, Santa Maria, 2014.

PALMA, J.C.F. A importância do PPCI para a sociedade: Avaliação baseada na percepção dos profissionais, usuários das edificações e idealizador da Lei Kiss. 2016. 81 f. Monografia (Departamento de Engenharia Civil), Universidade Federal do Rio Grande do SUL, UFRGS, Porto Alegre, 2016.

RIO GRANDE DO SUL, Lei Complementar $n^{\circ}$ 14.555, de 02 de julho de 2014. Diário Oficial do Estado do Rio Grande do Sul, Poder Executivo, Porto Alegre, RS, 03 jul. 2014. Disponível em: https://bit.ly/2DysvCz. Acesso em: 17 mar. 2020.

. Lei Complementar $n^{\circ}$ 14.376, de 26 de dezembro de 2013. Diário Oficial do Estado do Rio Grande do Sul, Poder Executivo, Porto Alegre, RS, 26 dez. 2013. Disponível em: https://bit.ly/ 3gxmC7d. Acesso em: 17 mar. 2020.

SILVEIRA, C.R. PPCI - Plano de prevenção contra incêndios - Projeto e implantação em edificações públicas em Porto Alegre. 2011. 64f. Monografia (Departamento de Engenharia Mecânica), Universidade Federal do Rio Grande do Sul, Porto Alegre, 2011.

UMINSKI, A.S.C. Técnicas de prevenção e combate a sinistros. Santa Maria, RS: Colégio Nossa senhora de Fátima, 2003. 
